\title{
The effect of carbon dioxide on the sensitivity of Bacteroides fragilis to certain antibiotics in
}

H. R. INGHAM, J. B. SELKON, A. A. CODD, AND J. H. HALE

From the Regional Public Health Laboratory, Newcastle upon Tyne

SYNOPS IS The effect of $10 \%$ carbon dioxide on the sensitivity to four antibiotics of 10 strain of Bacteroides fragilis was studied. The minimum inhibitory concentrations of erythromycin and lincomycin hydrochloride for these strains were four to 32 times higher, when grown i hydrogen plus $10 \%$ carbon dioxide, than the values obtained when the strains were grow⿳亠口冋. in pure hydrogen. A similar effect was obtained by growing the strains in hydrogen on as acid medium. Except for Haemophilus influenzae and Clostridium tertium the sensitivity to erythromycin and lincomycin hydrochloride of other species of bacteria examined was nof affected by the atmosphere in which the tests were carried out. 7-Chlorolincomycin and rifo mycin B diethylamide, to which the strains of $B$. fragilis were uniformly sensitive, were nof significantly affected by additional carbon dioxide.

The possible mechanisms underlying this phenomenon and its clinical implications ae discussed, and a case report describing the successful use of erythromycin in the treatment of cerebral abscess due to $B$. fragilis is presented.

In a recent study in this laboratory of the sensitivity to antibiotics of B.fragilis the majori of strains were found to be inhibited by $0.15 \mu \mathrm{g} / \mathrm{ml}$ of erythromycin and by $0.55 \mu \mathrm{g} / \mathrm{ml}$ of lincomycin hydrochloride (Ingham, Selkon, Codd, and Hale, 1968). After this work had been completed hydrogen plus $10 \%$ carbon dioxide was substituted for pure hydrogen the anaerobic technique. Strains of $B$. fragilis isolated on routine culture now appeared to be relatively resistant to erythromycin and lincomycin hydrochloride when their sensitivity was examined by the disc diffusion method. A more detailed investigation of this phenomenom was carried out, the results of which are reported here. The opportunity was also taken examine the susceptibility of $B$. fragilis to two new antibiotics, namely, 7-chlorolincomyc and rifamycin $B$ diethylamide.

\section{Materials and Methods}

\section{STRAINS}

The following strains were obtained from the National Collection of Type Cultures, Colindale, London: Bacteroides fragilis 9343, Clostridium welchii $8246, C l$. sporogenes $276, C l$. septicum 547 , Cl. histolyticum 503, Cl. tertium 541, Cl. tetani 279, and the Oxford staphylococcus strain 6571. B. fragilis strains B558 and B571 were kindly supplied by Dr S. M. Finegold, Department of Medicine, Wadsworth Veterans Hospital, California, USA. B. fragilis strains $15,17,21,26$, Received for publication 1 July 1969.
29,38 , and 41 were described in the previotrs study (Ingham et al, 1968). One strain each of Haemophilus influenzae, Lancefield group streptococcus, and Streptococcus faecalis we isolated in this laboratory and identified by standard procedures.

\section{ANTIBIOTICS SENSITIVITY TESTS}

Doubling dilutions of each of the four antibioties were prepared in nutrient broth at $p \mathrm{H} \mathrm{7,} \mathrm{except}$ for rifamycin $B$ diethylamide where the diluegt was phosphate buffer at $p \mathrm{H} 6$. The four series of doubling dilutions were incorporated in 
The effect of carbon dioxide on the sensitivity of Bacteroides fragilis to certain antibiotics in vitro

\begin{tabular}{|c|c|c|c|c|c|c|c|c|}
\hline \multirow[t]{3}{*}{ Strain } & \multicolumn{8}{|c|}{ Minimum Inhibitory Concentration $(\mu \mathrm{g} / \mathrm{ml})$} \\
\hline & \multicolumn{2}{|c|}{ Erythromycin } & \multicolumn{2}{|l|}{ Lincomycin } & \multicolumn{2}{|c|}{ 7-Chlorolincomycin } & \multicolumn{2}{|c|}{$\begin{array}{l}\text { Rifamycin B } \\
\text { Diethylamide }\end{array}$} \\
\hline & Hydrogen & $\begin{array}{l}\text { Hydrogen } \\
\text { and } 10 \% \\
\text { Carbon } \\
\text { Dioxide }\end{array}$ & Hydrogen & $\begin{array}{l}\text { Hydrogen } \\
\text { and } 10 \% \\
\text { Carbon } \\
\text { Dioxide }\end{array}$ & Hydrogen & $\begin{array}{l}\text { Hydrogen } \\
\text { and } 10 \% \\
\text { Carbon } \\
\text { Dioxide }\end{array}$ & Hydrogen & $\begin{array}{l}\text { Hydrogen } \\
\text { and } 10 \% \\
\text { Carbon } \\
\text { Dioxide }\end{array}$ \\
\hline $\begin{array}{l}\text { Oxford staphylococcus } \\
\text { B558 } \\
\text { B571 } \\
\text { NCTC } 9343 \\
15 \\
17 \\
21 \\
26 \\
29 \\
38 \\
41\end{array}$ & $\begin{array}{l}0 \cdot 15 \\
0 \cdot 3 \\
0 \cdot 3 \\
0 \cdot 3 \\
0 \cdot 15 \\
0 \cdot 3 \\
0 \cdot 3 \\
0 \cdot 15 \\
0 \cdot 15 \\
0 \cdot 3 \\
0 \cdot 3\end{array}$ & $\begin{array}{l}0 \cdot 3 \\
2 \cdot 5 \\
1 \cdot 25 \\
2 \cdot 5 \\
2 \cdot 5 \\
2 \cdot 5 \\
2 \cdot 5 \\
5 \cdot 0 \\
1 \cdot 25 \\
5 \cdot 0 \\
1 \cdot 25\end{array}$ & $\begin{array}{l}0.5 \\
1 \cdot 1 \\
0 \cdot 26 \\
0 \cdot 5 \\
0 \cdot 26 \\
0 \cdot 5 \\
0 \cdot 5 \\
0 \cdot 26 \\
0 \cdot 26 \\
0 \cdot 5 \\
0 \cdot 26\end{array}$ & $\begin{array}{l}0 \cdot 5 \\
2 \cdot 2 \\
4 \cdot 4 \\
4 \cdot 4 \\
4 \cdot 4 \\
4 \cdot 4 \\
2 \cdot 2 \\
4 \cdot 4 \\
1 \cdot 1 \\
2 \cdot 2 \\
4 \cdot 4\end{array}$ & $\begin{array}{l}0.07 \\
0.3 \\
0.6 \\
0.15 \\
0.35 \\
0.15 \\
0.15 \\
0.15 \\
0.035 \\
0.07 \\
0.3\end{array}$ & $\begin{array}{l}0 \cdot 15 \\
0 \cdot 3 \\
0 \cdot 6 \\
0 \cdot 3 \\
0 \cdot 3 \\
0 \cdot 15 \\
0 \cdot 3 \\
0 \cdot 3 \\
0 \cdot 15 \\
0 \cdot 15 \\
0 \cdot 6\end{array}$ & $\begin{array}{l}0 \cdot 608 \\
0 \cdot 15 \\
0 \cdot 15 \\
0 \cdot 15 \\
0 \cdot 15 \\
0 \cdot 15 \\
0.035 \\
0.07 \\
0 \cdot 15 \\
0 \cdot 15 \\
0.07\end{array}$ & $\begin{array}{l}0.008 \\
0.3 \\
0.3 \\
0.3 \\
0 \cdot 15 \\
0.6 \\
0 \cdot 15 \\
0.3 \\
0.3 \\
0.3 \\
0.3\end{array}$ \\
\hline
\end{tabular}

Table I A comparison of the sensitivity to erythromycin, lincomycin hydrochloride, 7-chlorolincomycin, and rifamycin $B$ diethylamide, of 10 strains of Bacteroides fragilis cultured in hydrogen and hydrogen plus $10 \%$ carbon dioxide

nutrient agar plus $5 \%$ defibrinated horse blood at $50^{\circ} \mathrm{C}$. Plates were dried for two hours at $37^{\circ} \mathrm{C}$ and inoculated with suspensions of $B$. fragilis in nutrient broth, using a phage typing apparatus. These suspensions were prepared by emulsifying sufficient growth from a 48-hour culture on blood agar in $2 \mathrm{ml}$ of broth to produce a just visible turbidity; this was then diluted 1 part in 5 parts. Such suspensions were shown to contain approximately $10^{5}$ organisms per ml. An overnight broth culture of the Oxford staphylococcus diluted 1 in 500 in broth was used as the control. The tests were carried out in duplicate, one series being incubated for 48 hours at $37^{\circ} \mathrm{C}$ in an atmosphere of pure hydrogen and the other in hydrogen plus $10 \%$ carbon dioxide in a Mackintosh and Fildes anaerobic jar fitted with a cold catalyst. The minimum inhibitory concentration was defined as the lowest concentration producing a marked decrease in colony size or permitting the growth to normal size of not more than 19 colonies.

Minimum bactericidal concentrations of 7-chlorolincomycin and rifamycin B diethylamide were determined by inoculating the suspensions of B. fragilis with a wire loop over an area $1 \mathrm{~cm}$ in diameter on standard grade Oxoid membrane filters lying on the surface of blood agar plates containing doubling dilutions of these antibiotics. The plates were incubated in hydrogen plus $10 \%$ carbon dioxide for 48 hours at $37^{\circ} \mathrm{C}$ when the MICs were determined. Those filters on which growth was inhibited or absent were transferred to antibiotic-free blood agar plates which were then incubated in the same atmosphere for a further 48 hours at $37^{\circ} \mathrm{C}$. Bactericidal endpoints were read using 20 or more colonies as the definition of significant growth. The quantity of antibiotics carried over by the filters to the antibiotic-free plates was determined by inoculating the filters after transfer with one loopful of 1 in 500 dilution of an overnight broth culture of the Oxford staphylococcus Inhibition of growth of the Oxford staphylococcus after incubation of the filters for 48 hours at $37^{\circ} \mathrm{C}$ on the antibiotic-free plates was related to the concentration of antibiotic in the plates from which the filter has been transferred, and as the MIC of the organism was known the percentage of antibiotic carried over could be calculated.

Disc sensitivity tests were performed in duplicate on $5 \%$ blood agar plates using paper discs containing erythromycin $5 \mu \mathrm{g}$ and lincomycin hydrochloride $2 \mu \mathrm{g}$. Strains were inoculated on to the medium with a wire loop so as to produce a semi-confluent growth after incubation in hydrogen or hydrogen plus $10 \%$ carbon dioxide at $37^{\circ} \mathrm{C}$ for 48 hours when the sizes of the zones of inhibition were measured.

\section{Results}

Preliminary examination of the sensitivity to erythromycin and lincomycin hydrochloride of 10 strains of $B$. fragilis by the disc technique revealed that all strains showed considerable reduction in the size of the zones of inhibition produced by these antibiotics when cultured in hydrogen plus $10 \% \mathrm{CO}_{2}$ instead of pure hydrogen. In many instances colonies were present within the zone of inhibition of growth often adjacent to the edge of the disc. The sensitivity to erythromycin and lincomycin hydrochloride of the other species of bacteria examined did not appear to be significantly affected by the atmosphere in which the tests were carried out, except $\mathrm{Cl}$. tertium and $H$. influenzae which were less sensitive to lincomycin hydrochloride and erythromycin 


\begin{tabular}{|c|c|c|c|c|}
\hline \multirow[t]{2}{*}{ Strain } & \multicolumn{2}{|c|}{ 7-Chlorolincomycin } & \multicolumn{2}{|c|}{ Rifamycin B Diethylamide } \\
\hline & MIC & $M B C$ & MIC & $M B C$ \\
\hline \multicolumn{3}{|l|}{ Oxford } & & \\
\hline $\begin{array}{l}\text { staphylococcus } \\
\text { B558 }\end{array}$ & $\begin{array}{l}0.15 \\
0.3\end{array}$ & $\begin{array}{l}5.0 \\
0.6\end{array}$ & $\begin{array}{l}0.008 \\
0.3\end{array}$ & $\begin{array}{l}0.017 \\
>2.5\end{array}$ \\
\hline B571 & 0.6 & $1 \cdot 25$ & 0.3 & 2.5 \\
\hline NCTC 9343 & 0.3 & $0 \cdot 3$ & $0 \cdot 3$ & $1 \cdot 25$ \\
\hline 15 & $0 \cdot 3$ & 1.25 & 0.15 & $>2.5$ \\
\hline 17 & $0 \cdot 15$ & 0.3 & 0.6 & $>2.5$ \\
\hline 21 & 0.3 & $0 \cdot 3$ & $0 \cdot 15$ & 0.6 \\
\hline 26 & $\mathbf{0} \cdot \mathbf{3}$ & $0 \cdot 3$ & $0 \cdot 3$ & 1.25 \\
\hline 29 & $0 \cdot 15$ & 0.3 & 0.3 & 0.6 \\
\hline 38 & $0 \cdot 15$ & $0 \cdot 3$ & 0.3 & $>2.5$ \\
\hline 41 & 0.6 & $1 \cdot 25$ & $0 \cdot 3$ & $>2.5$ \\
\hline
\end{tabular}

Table II The minimum inhibitory and minimum bactericidal concentrations of 7-chlorolincomycin and rifamycin $B$ diethylamide for strains of $\mathrm{B}$. fragilis grown in hydrogen plus $10 \%$ carbon dioxide

respectively when cultured in hydrogen plus $10 \%$ carbon dioxide.

The results of the plate sensitivity tests showed that when the plates were incubated in hydrogen plus $10 \%$ carbon dioxide the MICs of erythromycin and lincomycin hydrochloride for the 10 strains of $B$. fragilis examined were four to 32 times greater than those obtained when the tests were carried out in pure hydrogen (Table I). The minimum inhibitory concentrations of these antibiotics for the Oxford staphylococcus were not significantly different under these cultural conditions. The minimum inhibitory concentrations of 7-chlorolincomycin and rifamycin B diethylamide for these strains of $B$. fragilis when grown in hydrogen plus $10 \% \mathrm{CO}_{2}$ were the same as, or two to four times greater than, those obtained in pure hydrogen.

The minimum bactericidal concentrations of 7-chlorolincomycin for $\boldsymbol{B}$. fragilis were two to four times the MICs; rifamycin B diethylamide did not exert any consistent bactericidal effect against $B$ fragilis although it was bactericidal for the Oxford staphylococcus at a concentration twice the minimum inhibitory concentration. The carry over of both 7-chorolincomycin and rifamycin B diethylamide by the membrane filter was less than $3 \%$ (Table II).
The effect of $10 \% \mathrm{CO}_{2}$ on erythromycin wass studied by preparing in triplicate $5 \%$ blood aga? plates containing doubling dilutions of the ant biotics. One set of plates was immediately inoculated with one drop $(0.03 \mathrm{ml})$ of a 1 in 508 dilution of an overnight broth culture of the Oxford staphylococcus and incubated aerobicall at $37^{\circ} \mathrm{C}$ for 18 hours when the MIC was found to be $0 \cdot 15 \mu \mathrm{g} / \mathrm{ml}$. The other two series of plates were pre-incubated in hydrogen or hydrogen plu的 $10 \% \mathrm{CO}_{2}$ for 18 hours at $37^{\circ} \mathrm{C}$ before inoculation with the Oxford staphylococcus. These plates were incubated aerobically for a further 18 hours when the MIC of erythromycin was found to be $0 \cdot 15 \mu \mathrm{g} / \mathrm{ml}$ in both series. It was thus not possible to demonstrate any loss in activity of erythros mycin after a previous incubation in the presenç of $10 \%$ carbon dioxide.

In order to determine whether the lower $p \stackrel{\text { \$ }}{\mathbf{T}}$ resulting from the incubation of media in hydrq gen plus $10 \% \mathrm{CO}_{2}$ could be responsible for the increase in resistance of $B$. fragilis to erythroo mycin and lincomycin hydrochloride $5 \%$ horse blood agar plates were prepared at $\mathrm{pH} 7 \cdot 0,6.5$ and 6.0 respectively. The sensitivity to these antibiotics of three strains of $B$. fragilis and several other species of bacteria was examine $\mathscr{Q}_{1}$ on these media using discs containing erythromycin $5 \mu \mathrm{g}$ and lincomycin $2 \mu \mathrm{g}$, the plates being incubated in pure hydrogen for three days $37^{\circ} \mathrm{C}$. At $p \mathrm{H} 6.5$ and 6.0 the three strains of $B$ fragilis were much more resistant to both ant $\frac{\tilde{D}}{2}$ biotics than at $p \mathbf{H}$ 7.0. A similar but less markes effect was observed with $H$. influenzae and the Oxford staphylococcus. The sensitivities of Strep. faecalis and Strep. pyogenes did not vary greatly over the $p \mathrm{H}$ range tested (Table III).

\section{Discussion}

The sensitivity in vitro of $B$. fragilis to erythroo mycin as reported by different authors has varied considerably. Thus, the majority of the

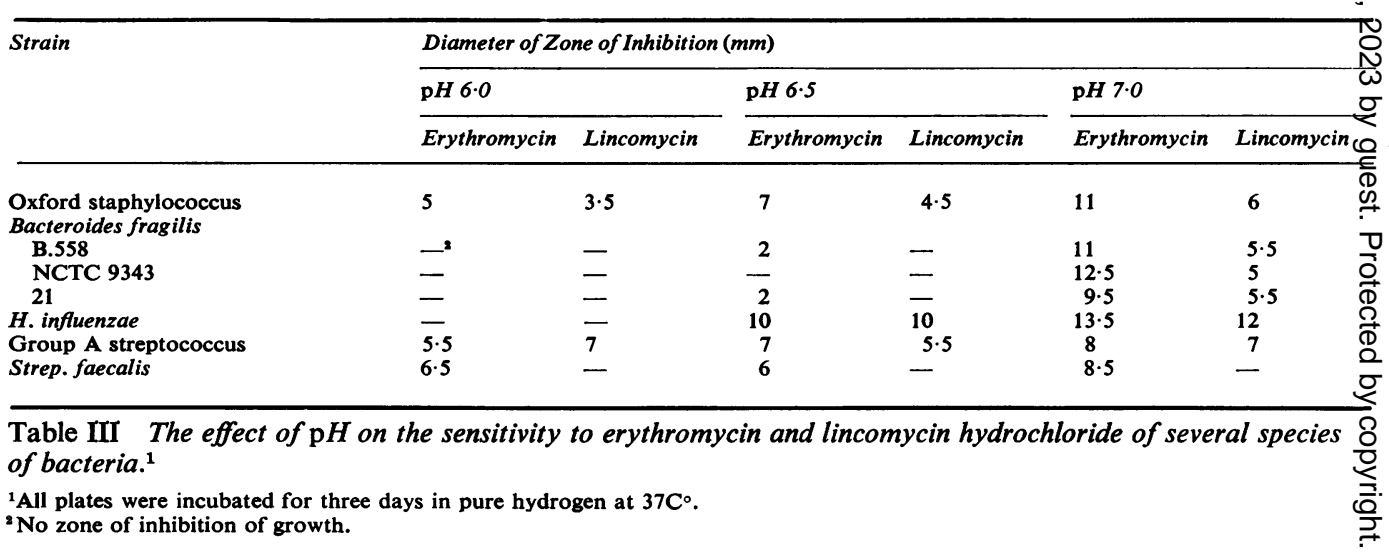




\begin{tabular}{|c|c|c|c|}
\hline \multirow[t]{2}{*}{ Author(s) } & \multirow{2}{*}{$\begin{array}{l}\text { Number } \\
\text { of } \\
\text { Strains }\end{array}$} & \multicolumn{2}{|c|}{$\begin{array}{l}\text { Minimum Inhibitory Concentration } \\
\text { of Erythromycin }(\mu \mathrm{g} / \mathrm{ml})\end{array}$} \\
\hline & & Range & Median Value \\
\hline $\begin{array}{l}\text { Garrod (1955) } \\
\text { Gillespie and Guy }\end{array}$ & 23 & $2->4$ & $>4$ \\
\hline (1956) & 10 & $0 \cdot 06-4$ & $0 \cdot 25-0 \cdot 5$ \\
\hline Hoogendijk (1965) & 13 & $0 \cdot 25-2$ & \\
\hline Finegold et al (1967) & 47 & $0.4-400$ & $6 \cdot 2$ \\
\hline Ingham et al (1968) & 26 & $0 \cdot 03-0.3$ & $0 \cdot 15$ \\
\hline
\end{tabular}

Table IV The sensitivity of Bacteroides fragilis to erythromycin

strains examined by Garrod (1955), Hoogendijk (1965), and Finegold, Harada, and Miller (1967) had MICs of greater than $1 \mu \mathrm{g} / \mathrm{ml}$, and most of the strains examined by Gillespie and Guy (1956) had minimum inhibitory concentrations of $0.5 \mu \mathrm{g} / \mathrm{ml}$ or more, whereas the majority of the strains examined by Ingham et al (1968) had MICs of $0.15 \mu \mathrm{g} / \mathrm{ml}$ (Table IV). In all these studies except that of Ingham et al (1968), the sensitivity tests were carried out anaerobically in the presence of $5 \%$ or $10 \%$ carbon dioxide. The present report has shown that it was the addition of $\mathrm{CO}_{2}$ which was responsible for the difference between the results of the sensitivity to erythromycin obtained by Ingham et al (1968) and these other authors. Similarly the difference between the MIC of lincomycin for B. fragilis found by Ingham et al (1968), namely, $0.55 \mu \mathrm{g} / \mathrm{ml}$ and of $6.2 \mu \mathrm{g} / \mathrm{ml}$ found by Finegold et al (1967), has also been shown by the present report to be due to the addition by the latter authors of $10 \% \mathrm{CO}_{2}$ to the anaerobic environment used to culture this organism. About the same degree of reduction in sensitivity to erythromycin and lincomycin as was produced by the addition of $10 \%$ carbon dioxide was produced by altering the $p \mathrm{H}$ of the culture medium from $7 \cdot 0$ to 6.0 . Furthermore, this effect of $p \mathrm{H}$, like that of carbon dioxide, did not apply equally to all organisms. It was most marked with $B$. fragilis, nearly as marked with $H$. influenzae, but much less apparent with the Oxford staphylococcus, a group A streptococcus, and Streptococcus faecalis. This suggests that this effect of the carbon dioxide results from its increasing the acidity of the culture medium. The alternative hypothesis that the carbon dioxide reduces the sensitivity of the $B$. fragilis and $H$. influenzae by stimulating an alternative biochemical pathway is unlikely since the addition of carbon dioxide did not significantly reduce the activity of 7-chlorolincomycin, a derivative of lincomycin. Furthermore there is previously published evidence that erythromycin has reduced activity at an acid $p \mathrm{H}$ (Haight and Finland, 1952; Garrod and Waterworth, 1956) and it has been suggested that this results from alterations in physicochemical factors concerned in the penetration of antibiotics into the bacterial cell. Thus, Sabath, Gerstein, Loder, and Finland (1968) observed that the total concentration of erythro- $c$ mycin required to inhibit the growth of Escher- $\cong$ ichia coli increased as the $p \mathrm{H}$ fell whereas the $\frac{\sigma}{5}$ antibacterial activity of the un-ionised fraction $\stackrel{\&}{\rightleftarrows}$ remained constant over the $p \mathrm{H}$ range 5.5 to $\underline{\sigma}$ 8.5. These authors and others (Abraham and Duthie, 1946; Crane, 1921; Albert, 1968) suggest $\stackrel{\vec{\rho}}{\rightarrow}$ that it is the un-ionised molecules which enter $\bar{O}$ the bacterial cell. However, Albert (1968), study- 믐 ing the antibacterial action of acridines, has $\frac{\bar{c}}{\sigma}$ shown that jonised molecules are not inactive $\stackrel{\varnothing}{\varnothing}$ but that their activity is reduced by the presence of hydrogen ions which, he suggests, compete for important anionic groups on the surface of the $\bigcirc$ bacterial cell. The greater susceptibility of $\overrightarrow{\vec{\omega}}$ $B$. fragilis and $\boldsymbol{H}$. influenzae to the effect of $\stackrel{\omega}{\sigma}$ carbon dioxide on the activity of erythromycin and lincomycin, compared with other organisms studied, may be due to differences at the site $\underset{\omega}{\omega}$ on the bacterial wall where absorption of these $i$ antibiotics occurs. A somewhat similar explana- on tion has been advanced by Eagle, Levy, and 을 Fleischman (1952) for the difference in the effect of $p \mathrm{H}$ on the action of tetracycline against $D$ Staphylococcus aureus and Escherichia coli.

The marked influence of 5 to $10 \% \mathrm{CO}_{2}$ and of $p \mathrm{H}$ on the sensitivity of $B$. fragilis to erythromycin and lincomycin poses the question whether a sensitivity test to these agents in the presence of added $\mathrm{CO}_{2}$ is more appropriate in relation to conditions pertaining in vivo than a test carried out in the presence of pure hydrogen as described in our previous report (Ingham et al, 1968). The partial pressure of $\mathrm{CO}_{2}$ in $\mathrm{mm}$ of mercury varies from $40 \mathrm{~mm}$ in arterial blood to $46 \mathrm{~mm} \cong$ in venous blood. Although this is equivalent to approximately $5 \% \mathrm{CO}_{2}$ only a small proportion of this is in solution, the remainder being in the form of bicarbonate or combined with protein as carbamino compounds (Campbell and Dickinson, 1960). Pus may on occasion have a $p \mathrm{H}$ below 6.0 (Rous, 1925). On the other hand the $p \mathrm{H}$ of body fluids is 7.4 so that in healthy tissue, and this includes the extending edge of an inflammatory site, the action of these two antibiotics $\frac{D}{0}$ would be unimpaired. The answer to this question has clearly to be sought from a controlled trial of $N$ lincomycin and 7-chlorolincomycin. In the ab- N sence of this evidence it may perhaps be safer $N$ to use the latter agent in preference to linco- $C$ mycin since its action on $B$. fragilis in vitro is not significantly affected by the concentrations of carbon dioxide and variations in $p \mathrm{H}$ likely $\stackrel{\odot}{\oplus}$ to be encountered in vivo.

Although concentrations of $\mathrm{CO}_{2}$ attained in the body under certain conditions might be

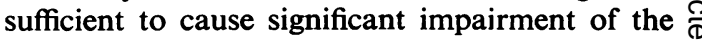
antibacterial activity of erythromycin, clinical $\cong$ experience in the use of this antibiotic suggests that it has been effective. The following case 8 history is presented in support of this statement.

A male patient, aged 53 years, was admitted with a right temporal lobe abscess secondary 
to right chronic otitis media. The abscess was drained and a mastoidectomy performed. Culture of pus aspirated from the abscess yielded a scanty growth of Proteus species and coliforms and a heavy growth of Bacteroides fragilis; the latter organism was sensitive to tetracycline and chloramphenicol. Treatment with chloramphenicol $250 \mathrm{mg}$ six-hourly for 10 days resulted in a marked clinical improvement, and aspirates obtained from the abscess cavity were sterile on culture. Chloramphenicol was withdrawn and sulphamethazine substituted. Relapse subsequently occurred with accumulation of pus which yielded $B$. fragilis on culture. Treatment with chloramphenicol, $500 \mathrm{mg}$ six-hourly, and frequent surgical drainage over a period of three weeks failed to eradicate the infection. Further drainage of the abscess was carried out and erythromycin, $100 \mathrm{mg}$ intramuscularly eight-hourly, given in addition to chloramphenicol. Within 10 days of commencing therapy with erythromycin the patient became apyrexial and there was no further accumulation of pus. The administration of chloramphenicol was stopped at this stage and erythromycin was given orally in a dose of $250 \mathrm{mg}$ six-hourly for a further four weeks.

The patient was discharged three months after admission and there has been no recurrence of infection during the past 18 months.

We would like to thank Mr J. C. Hankinson for permission to publish details of his patient, also Messrs Upjohn Ltd. who supplied lincomycin hydro- chloride and 7-chlorolincomycin, and Lepetit Ltd ${ }^{C}$ who provided a supply of rifamycin B diethylamide

\section{References}

Abraham, E. P., and Duthie, E. S. (1946). Effect of $p \mathrm{H}$ of the medium on activity of streptomycin and penicillin. Lance $1,455-459$.

Albert, A. (1968). Selective Toxicity, 4th ed., p. 264. Methuen? London.

Campbell, E. J. M., and Dickinson, C. J. (1960). Clinical Phys ology, p. 103. Blackwell, Oxford.

Crane, M. M. (1921). Effect of hydrogen ion concentration o toxicity of alkaloids for paramoecium. J. Pharmaco $\mathbb{D}$ exp. Ther., 18, 319.

Eagle, H., Levy, M., and Fleischman, R. (1952). The effect of the $p \mathrm{H}$ of the medium on the antibacterial action of penicillin, streptomycin, chloramphenicol, terramycin and bacitracin. Antibiotics and Chemotherapy, 2, 563-575.

Finegold, S. M., Harada, N. E., and Miller, L. G. Antibioti susceptibility patterns as aids in classification and characo terization of gram-negative amaerobic bacilli. J. Bact., 94 तु
1443-1450.

Garrod, L. P. (1955). Sensitivity of four species of bacteroides tî antibiotics. Brit. med.J., 2, 1529-1531.

Garrod, L. P., and Waterworth, P. M. (1956). Behaviour in vitrï of some new antistaphylococcal antibiotics. Brit. med. Jîn

2,61-65.
Gillespie, W. A., and Guy, J. (1956). Bacteroides in intra-ab dominal sepsis. Lancet, 1, 1039-1042.

Haight, T. H., and Finland, M. (1952). The antibacterial action. of erythromycin. Proc. Soc. exp. Biol. (N.Y.), 81, 175-183

Hoogendijk, J. L. (1965). Resistance of some strains of Bacteroide to ampicillin, methicillin and cloxacillin. Antonie Leeuwenhoek, 31, 383-385.

Ingham, H. R., Selkon, J. B., Codd, A. A., and Hale, J. $\overrightarrow{H 0}$ (1968). A study in vitro of the sensitivity to antibiotics of Bacteroides fragilis. J. clin. Path., 21, 432-436.

Rous, P. (1925). The relative reaction within living mammaliab tissues. IV. Indicated differences in the reaction of thP organs on vital staining with phthaleins. J. exp. Med., 41 739-759.

Sabath, L. D., Gerstein, D. A., Loder, P. B., and Finland, Me्व (1968). Excretion of erythromycin and its enhanced activit in urine against gram-negative bacilli with alkalinization J. Lab. clin. Med., 72, 916-923. 